\title{
Trauma, Proximity, and Developmental Psychopathology: The Effects of War and Terrorism on Children
}

\author{
Daniel S Pine*,1,2,3 Jane Costello ${ }^{1,2,3}$ and Ann Masten ${ }^{1,2,3}$ \\ 'Section on Development and Affective Neuroscience, National Institute of Mental Health Intramural Research Program, Bethesda, MD, USA; \\ ${ }^{2}$ Developmental Epidemiology Program, Department of Psychiatry and Behavioral Sciences, Duke University Medical School, Durham, NC, USA; \\ ${ }^{3}$ Institute of Child Development, University of Minnesota, Minneapolis, MN, USA
}

\begin{abstract}
This report summarizes recent literature relevant to the effects of terrorism on children's mental health. The paper addresses three aspects of this topic. In the first section of the paper, data are reviewed concerning the relationships among stress, trauma, and developmental psychopathology. A particular emphasis is placed on associations with indirect forms of trauma, given that terrorism involves high levels of indirect trauma. Second, the paper delineates a set of key principles to be considered when considering ways in which the effects of terrorism on children's mental health can be minimized. Third, data are reviewed from studies in developmental psychobiology. These data are designed to illustrate the mechanisms through which children exhibit unique effects in the wake of traumatic circumstances.

Neuropsychopharmacology (2005) 30, I78 I - 1792. doi:I0.1038/sj.npp. I3008 I4; published online I3 July 2005
\end{abstract}

Keywords: trauma; children; psychobiology; terrorism

\section{INTRODUCTION}

\section{The Effects of War and Terrorism on Children}

In this summary, we review what can be learned from the literature on traumatic exposure about the psychological effects of terrorism on children, and the implications for prevention and intervention planning. At the outset, it must be noted that virtually no research examines directly the psychological effects of terrorism on children. As a result, implications for prevention and intervention must come from related research that does not focus specifically on terrorism.

Three broad areas of research are reviewed. First, we review the behavioral and psychological effects of various forms of trauma, focusing particularly on the effects of 'distant traumas,' as this form of traumatic exposure appears most similar in form to the threat of terrorism. Throughout the review, we compare what is known about the responses of children to what is known about the responses of adults. Research generally indicates that most children recover quickly from exposure to traumatic events unless they are directly involved in harm to themselves or their family (Masten and Coatsworth, 1998; Pine and Cohen,

\footnotetext{
*Correspondence: Dr DS Pine, NIMH-Building 15-K, Room II0, MSC-2670, Bethesda, MD 20817-2670, USA,

E-mail: daniel.pine@nih.gov

Received 2 March 2004; revised 28 June 2004; accepted 20 July 2004 Online publication: 2 June 2005 at http://www.acnp.org/citations/ Npp060205040097/default.pdf
}

2002). However, a small minority can develop chronic problems following exposure even to distant trauma. While severity of traumatic exposure is a strong predictor of outcome, aspects of the child and the child's ecology also play a role (Masten and Coatsworth, 1998). This diversity of event- and child-related factors provides a range of potential targets for interventions designed to promote resilience. In the second section of this review, we summarize key principles to consider when evaluating the potential benefits of such interventions. Protective interventions, whether occurring naturally in the lives of children or implemented by professionals, can target many different processes at different system levels, ranging from cells (eg, medication) to social policy (eg, mandated school emergency planning). Regardless, many of the adverse effects of trauma and the moderating effects of protective factors or interventions are thought to operate by influencing functional aspects of the central nervous system. Moreover, there are individual and developmental differences in how the system responds to trauma. Therefore, in the third section, we review developmental plasticity in neural systems that are responsive to threats.

\section{STRESS, TRAUMA, AND PSYCHOPATHOLOGY IN CHILDREN AND ADOLESCENTS}

At some point before they reach adulthood, most children are exposed to one or more traumatic event involving 'actual or threatened death or serious injury, or other threat 
to one's physical integrity' (Costello et al, 2002). Some of these events are personal, caused either by accident or by deliberate violence against the child. Others, like natural disasters and mass accidents, can involve whole families or communities. Traumatic events can be placed on a continuum based on the degree to which a child is exposed directly to extremely frightening and prolonged stressors that carry long-term impact on personal well being or access to social supports. The most extreme traumas involve high degrees of threat, targeted directly at the child over long periods of time, that produce a loss of social supports. For example, one form of extreme trauma might involve witnessing a period of prolonged violence directed towards a parent that ultimately culminates in death of a parent. Alternatively, milder traumas involve exposures that either are brief in duration, only mildly threatening, or produce an increase in the availability of social support. For example, one form of relatively mild trauma might involve brief exposures to inter parental arguments that culminate in divorce and an actual decrease in exposure to violence (Hetherington, 1999).

A wealth of epidemiological studies examine the association between childhood psychopathology and these various forms of stress exposure, including direct exposure to a violent act (Pynoos et al, 1999), as well as relatively milder and more common stressful life events, such as breakup of a romantic relationship or relatively mild illnesses (Steinberg and Avenevoli, 2000; Hetherington, 1999). In general, the types of psychopathology exhibited by children following what DSM-IV calls 'extreme stressors,' as well as less severe life events, show broad similarities to the types of psychopathologies exhibited by adults. In particular, there are quite strong predictions from traumatic stress to emotional disorders, defined in DSM-IV as mood and anxiety disorders (Pynoos et al, 1999; Breslau, 2002; Pine et al, 2002). Some evidence suggests that traumatic events in children may also lead to behavior problems, such as those included in DSM-IV oppositional defiant disorder, conduct disorder, and attention deficit hyperactivity disorder (ADHD) (Shaw et al, 1995). However, these associations emerge with less consistency. Moreover, since few studies rely on prospective community-based longitudinal designs, findings in many available studies may be influenced by biases related to referral patterns or retrospective recall (Pine and Cohen, 2002; Pine et al, 2002). Therefore, it remains unclear the degree to which some psychiatric problems that emerged after a traumatic event might actually represent exacerbations of preexisting problems. For example, pre-traumatic behavior problems may actually shape the degree to which a child is exposed to various forms of traumatic stress (Champion et al, 1995).

Some researchers treat traumatic exposure as a continuum, from relatively mild to severe, and place more emphasis on the magnitude of overall stress, or the impact of moderating factors, than on the precise nature of the event. This view of trauma suggests that traumatic events produce a broad, generalized increase in risk for various forms of psychopathology (Steinberg and Avenevoli, 2000). From this perspective, the specific psychiatric outcome may have more to do with characteristics of the child than of the event.
Other research suggests that different forms of stress may be associated with different forms of psychopathology. Research in this area has categorized events based on the typical reaction produced by such an event in most children. For example, events that involve exposure to dangerous circumstances, such as exposure to violent acts, typically produce characteristic signs of fear in a child, whereas events that involve exposure to loss of vital relationships, such as decreased contact with a loved one, typically produce characteristic signs of dysphoria (Eley and Stevenson, 2000). Such distinctions between fear- and griefrelated reactions can be made relatively reliably, even among preschool children (Eley et al, 2003). In this area of research, events involving fear have been shown to exhibit close links to anxiety disorders, whereas events involving loss have been shown to exhibit close links to mood disorders (Eley and Stevenson, 2000; Kendler et al, 2003). It would follow from this perspective that the unique features of terrorism may contribute to risk for specific psychopathology in children.

Beyond the specific aspects of one or another traumatic event, different forms of trauma may be linked to psychopathology through the relationship between specific traumas and correlated patterns of other risk factors. These associated risk factors, acting in concert with specific aspects of the trauma, may mediate trajectories in symptom profiles. For example, parental psychopathology and disruption in the parent-child relationship might predict particularly high risks for psychopathology following exposure to domestic violence. Concerning contributions from parental psychopathology, considerable research examines the association between mood and anxiety disorders in parents and their children, as reviewed elsewhere (Weissman et al, 1997; Merikangas et al, 1999). This literature is not reviewed in the current summary, since few family-based studies have examined directly interactions between parental psychopathology and the psychological effects of traumatic exposure. Similarly, characteristics of the child, including their developmental stage or aspects of their psychobiology, may moderate the response to traumatic exposures. These influences are discussed below.

\section{Defining Exposure to Terrorism and Examining Associations with Behavior}

While exposure to traumatic events is very common during childhood, terrorism adds unique dimensions to traumatic exposure. For example, children may become targets of people who hate them for political rather than for personal reasons. Such events have the potential to increase children's perceptions of the uncertainty and risk in the world and cause psychological harm, even if experienced only at second or third hand.

Terrorism is a form of undeclared war that often targets the civilian population as well as, or instead of, the military. As such, terrorism often avoids formal engagement in battles in favor of unannounced attacks, often perpetrated (or carried out) by small groups operating from within a society rather than as an external, invading force. Terrorists can use rumors of potential disasters and traumatic events as effectively as real acts of terror. Children may face 
particular danger on their own account (eg, as the children of the President), as members of a specifically targeted group (eg, families of military personnel), as a vulnerable class of society (eg, because the death of children is so horrifying), or simply as randomly selected individuals. It is perhaps this combination of targeted hate and random violence that is particularly frightening. Terrorism combines two threats: of deliberate harm to a child's community and of random harm to children and their families. These characteristics pose special challenges to the emotional balance of a community, and they require unique responses from communities and care providers.

In other respects, however, terrorism shares key dimensions of other traumas. Features of traumatic events and experiences can be quantified with respect to their potential impact on the psychological well-being of individual children. These features include: (1) the degree of exposure to the event (victim, member of victimized group; victim of event's consequences (eg, famine following war), friend killed; witness to horrific events; exposure through media); (2) the amount of family support available during the experience and in the aftermath (parents killed, parents psychologically unavailable, parents supportive); (3) the amount of life disruption (orphan refugee, refugee with family, home and/or school damaged, little effect on home/ school life); and (4) the amount of social disorganization (social order collapses into chaos, emergency systems overwhelmed, or work effectively). Given the dearth of data examining the psychological effects of trauma in children and adolescents, data on other traumas provide important insights on terrorism, particularly given these similarities between terrorism and other traumas.

While traumatic exposure among children is common, exposure to some specific types of traumatic events is uncommon in the United States. Most American children have been extraordinarily protected from the extreme end of these dimensions, though there are important exceptions to this rule. Aside from children growing up in military families, it is rare for native-born children growing up in America to be direct victims of war or terrorism, to have parents killed in such events, or to become refugees as a result of them. Even so, most American children have been indirectly exposed to war and terror through media coverage or effects on family and friends, or effects on daily life (eg, security procedures). Moreover, the US is home to growing numbers of child and adolescent refugees who have been exposed to war and terrorism at first hand (US Committee for Refugees, 2004). Finally, large subpopulations of American children have been exposed to violent acts through circumstances endemic to some geographic areas in America, such as portions of large urban areas (Gorman-Smith and Tolan, 1998).

In this section, we briefly summarize literature examining the possible effects of terrorism on children, emphasizing what is known about the impact of indirect exposure to war and terrorism because this is the form of terror most likely to impact American children. Indirect exposure may occur through various avenues: (1) children learn about about the acts of terrorism against their country through coverage on $\mathrm{TV}$, the internet or other media, and through people they know talking about it; (2) children respond to how their parents react to such events; and, (3) events lead to changes in home or school life, such as increased police presence or surveillance, economic hardship, increased distrust of 'foreigners,' or even the erosion of civil society. In discussing such potential effects, Terr et al (1999) proposed the term 'distant trauma' to refer to 'the reaction (memory, thinking, symptoms) to a disastrous event, experienced at the time of the event, but from a remote and realistically safe distance.'

In an attempt to elucidate the risk children face when exposed to terrorism as opposed to other forms of trauma, we summarize literature on five different types of exposure, involving different levels of random violence, aggressive acts, and targeted hate: (1) personal exposure to war and terrorism, (2) natural disasters, (3) man-made accidents, (4) mass shootings, and (5) indirect exposure to war and terrorism. We do not review the extensive literature on childhood sexual abuse, as this literature has been reviewed extensively and appears less relevant to research on terrorism. Nevertheless, the summary of research in these five areas is informed by the considerable existing research on domestic physical and sexual abuse, as summarized extensively in recent publications (Bremner, 2002; Breslau, 2002; Kitzmann et al, 2003; Pine and Cohen, 2002; Wolfe et al, 2003; Yehuda, 2002).

Finally, research methods vary considerably across the five classes of traumatic exposure, and few studies have been conducted on any single class of event. Moreover, the current review adopts a broad perspective, focusing on behavioral outcomes as well as implications for research on interventions and neurobiology. As a result, the current summary does not provide a quantitative meta-analysis of outcome data, but rather broadly reviews exemplary studies. For interested readers, Pine and Cohen (2002) recently provided such a semiquantitative review, based on data in prospective community-based studies of trauma exposure during childhood. In general, rates of posttraumatic stress disorder (PTSD) in the reviewed studies rarely exceed $25 \%$ of exposed children, unless large groups of children are exposed to very high degrees of extreme trauma. Similarly, the magnitude of the risk in these studies for any form of psychopathology, including PTSD as well as other emotional or behavioral disorders, typically involves a two-to-four-fold increased risk for some clinically impairing condition in the exposed as compared to unexposed groups.

\section{Personal Exposure to War and Terrorism}

The psychological effects on children of war or terrorism have been studied through research on various events occurring since World War II. Examples include the Holocaust (Sagi-Schwartz et al, 2003), the Belfast riots in Northern Ireland (Lyons, 1979), the Iraqi occupation of Kuwait (Hadi and Llabre, 1998), the ongoing saga of ethnic rivalry in Sri Lanka (Chase et al, 1999), the effects of the current situation in the Middle East (Schwarzwald et al, 1993; Thabet and Vostanis, 1999; Thabet et al, 2004), and ethnic cleansing in Cambodia (Mollica et al, 1997) or Rwanda (Dyregrov et al, 2000).

As found in research on adults, virtually all of these studies find a dose-response effect: the more directly a child lies in harm's way, the more severe the risk of PTSD. Similar 
dose gradients have been observed in research on child maltreatment (Masten and Wright, 1998). Clearly, 50-80\% of children will show at least some signs of PTSD when they directly experience intense threats, as posed, for example, by tear-gas attacks (Thabet and Vostanis, 2000), witnessing the murder or beating of their parents (Chase et al, 1999; Sack et al, 1999; Thabet and Vostanis, 1999), or by neardeath experiences (Sack et al, 1999). Many studies of trauma in children have found that direct injury to self, parents, and other close people is associated with more trauma symptoms (Pine and Cohen, 2002). Moreover, traumatic experiences during war rarely occur in isolation, and high cumulative exposure levels are related to higher symptom levels, with rates of acute PTSD symptoms surpassing 75\% in some situations (Hubbard et al, 1995; Wright et al, 1997).

The study of children from refugee camps is equivocal from the viewpoint of 'distant trauma'. Several researchers have concluded that events threatening survival of self or parents are much more likely to lead to PTSD than experiences related to forced removal from home, as typically experienced in refugee camps (Sack et al, 1999; Dyregrov et al, 2000; Mollica et al, 1997; Allwood et al, 2002). However, refugee camps can still be extremely dangerous environments where children are exposed to horrifying trauma. Also, the exposure of these children is real, rather than 'from a remote and realistically safe distance.' On the other hand, these children may be less exposed to direct trauma than children living in regions actively involved in a war. The majority of studies in this area have found relatively high rates of PTSD in refugee camps, generally exceeding 10\% (Allwood et al, 2002; Papageorgiou et al, 2000; Stein et al, 1999; Weine et al, 1995), and surprisingly low rates of other emotional and behavioral symptoms (Dybdahl, 2001).

\section{Exposure to Distant Trauma}

In this section, we review the literature on the effects of distant or indirect traumatic exposure to natural disasters, mass accidents, school shootings, war, and terrorist attacks. When considering the potential effects of future terrorist attacks, distant trauma is the most likely type of exposure for most American children.

Natural disasters. While natural disasters can involve violence and extreme threat, they lack the element of targeted hate. Nevertheless, research on natural disasters informs the potential reactions of children to terrorism since natural disasters involve indirect traumatic exposure that can affect large groups of children who are not directly harmed physically by the event. Considerable heterogeneity exists in the outcome following such traumatic events. On the whole, children seem to be remarkably resilient in the face of natural disasters unless the disaster results in death or injury to family members, or dislocation of home life (Masten et al, 1990). However, in a minority of cases, children can develop chronic psychopathology following this form of trauma (Pine and Cohen, 2002; Pine et al, 2002).

What factors contribute to the resilience that most children show, and what predicts the adverse outcomes that occur in the minority of cases? As noted above, effects on family members can moderate outcomes of direct exposures (Luthar, 2003), but few studies examine moderators of associations between childhood psychopathology and the indirect effects of natural disasters. Asarnow et al (1999) provide one of the few such studies using a pre-post, quasi-experimental design; in this study, investigators assessed participants in a family-genetic depression study both before and after the 1997 Northridge, California earthquake. The level of exposure was generally quite mild, but there was extensive exposure to the media reports of death and destruction. On the whole, children fared quite well. Pre-earthquake anxiety disorders, but no other diagnoses or family characteristics, predicted an increased level of post-earthquake PTSD scores, over and above the impact of resource loss.

Mass accidents - shipwrecks, fires, etc. These events may be the result of human error or culpable incompetence, but not of deliberate intent to harm. As in research on the effects of war, these events show a dose-response effect for children directly exposed to the trauma (Pine and Cohen, 2002). In terms of indirect exposure, effects on children not directly implicated appear fairly modest and short-lived, with odds ratios rarely exceeding, in terms of risk for psychopathology. For example, Terr et al (1999) examined the impact of the Challenger disaster on three groups of children: those who had made the trip to Florida for the launch, many of whom were third-grade classmates of astronaut and teacher Christie McAuliffe's son, students from Christie McAuliffe's home town in Concord, New Hampshire, who watched the launch live on television, and a group on the West coast who heard about the explosion later. Children who had the closest relationship to McAuliffe and saw the explosion live (regardless of whether it was in person or on TV) tended to suffer the most, suggesting a psychological 'dose-response' effect. There were less severe PTSD symptoms among the West coast group. Symptoms diminished sharply by a year later in all groups. Interestingly, contrary to research reviewed later on other traumatic exposures, children with previous traumatic exposures tended to react less to Challenger than did other children.

A particular subtype of man-made accident is damage to nuclear reactors, with its risk of future illness. Given this unique aspect of the event, one might anticipate a stronger association with psychopathology, relative to other accidents. However, as of this writing, children also appear resilient in the aftermath of such accidents. Studies of the effects of the Three Mile Island near-meltdown in 1981, and of the Chernobyl disaster in 1986 (Cornely and Bromet, 1986; Bromet et al, 2000) have shown few long-term effects on indirectly exposed children so far. Bromet and colleagues also found that the main effects on the children were mediated by maternal anxiety or depression.

School shootings. Like exposure to terrorist acts, school shooting incidents contain elements of both randomness and deliberate intent to harm, as well as being rare events with large potential impact (Moore et al, 2002). These incidents also occurred in a setting where adults have been entrusted by parents with protecting their children. In a study of the Columbine High school shootings (Brener et al, 
2002), data from the 1999 national Youth Risk Behavior Survey (YBRS) were used to show that children in the United States interviewed after the date of the shootings were more likely to feel too unsafe to go to school, as compared to those interviewed before the shooting. This was the case 'regardless of whether the school was in an urban, suburban, or rural area, but was especially pronounced in rural areas where the likelihood of students' missing school was more than 12 times higher after Columbine' (p. 148). There was no increase in any other symptoms measured in the YBRS.

The risk of imitation poses another disturbing effect of distant trauma. Kostinsky et al (2001) examined a database of threats of school violence reported to the Pennsylvania Emergency Management Agency, Harrisburg, during the 50 days following the Columbine incident. Threats of school violence numbered 354, far exceeding the one or two threats per year estimated by school administrators prior to 1999 . The frequency of these threats demonstrated a crescendodecrescendo pattern. In all, 56 percent of the threats were made on or before day 10 after the incident, and more than one-third occurred on days 8,9 , and 10 .

War and terrorism. The current report focuses explicitly on research relevant to potential future terrorist attacks on children in the United States. As such, prior studies examining the direct effects of war on children and adolescents are not directly relevant to the current report. Moreover, virtually no studies examine the effects of terrorism on children, though relevant data are reviewed immediately below. Among studies examining children exposed to war or terrorism as 'distant trauma,' most are fairly optimistic. Lyons' (1979) studies of the impact of the sectarian terrorism in Ireland on children in Belfast found that the main complaints were enuresis, fear of being left alone, and school refusal (details p. 386). The few cases that came to clinical attention appeared to involve children of anxious parents, once again suggesting that distal effects of trauma are mediated by proximal effects on parental functioning. Among these, younger patients had significantly milder symptoms.

Pfefferbaum et al (2003a) studied the effect of the bombing of the US embassy in Nairobi, Kenya, in which 253 people were killed and over 5000 injured. A survey of 500 children showed that, even among indirectly exposed children, reactions were more severe among those with a history of previous trauma, suggesting individual vulnerability. This is inconsistent with Terr's observations after the Challenger disaster described above, which implicated a moderating influence of trauma experience in the other direction, more consistent with an inoculation effect (Terr et al, 1999). Given these inconsistencies, further research is needed to clarify the role of vulnerability $v s$ protective processes that may moderate the associations between prior trauma and outcome following indirect exposure.

Some studies have noted that pre-exposure psychological characteristics of children and families moderate the impact of distant traumatic events on children's symptoms, as observed in adults as well as children directly exposed to trauma (Pine and Cohen, 2002). In Palestinian children, Thabet and colleagues (1999, 2000, 2004) found that children with high emotional and behavioral symptoms scores at the first assessment were the most likely to have persistent PTSD a year later. Studies of children in occupied Kuwait (Hadi and Llabre, 1998; Llabre and Hadi, 1997) found that social support moderated the effect on exposure on PTSD symptoms in girls, but not boys.

In the United States, the three recent major terrorist events to involve children are the initial Trade Center bombing in 1993, the Oklahoma City bombing in 1995, and the 2001 Trade Center bombing. Pfefferbaum et al (2003b) discuss all three in terms of direct $v s$ indirect exposure (eg, through the media). They argue that 'Examining indirectly exposed children is important especially in terrorist events, because a goal of terrorism is to inflict fear in the broader community' (p. 97). The general conclusion is that PTSD reaction scores were relatively low in indirectly exposed samples, and that children 'reported minimal impact on functioning' (p. 97).

In New York, the effects of the 9/11 Trade Center disaster appear to have been quite marked even among children only indirectly affected. Prevalence of psychiatric disorders in one study was two to three times as high in New York city school students as it was in closeby urban and suburban school students tested a year earlier (Hoven et al, 2003), though it is possible that Manhattan rates were higher before the bombings as well.

In conclusion, available research on trauma exposure in children and adolescents examines diverse kinds and severity of exposure. In terms of direct exposure, a doseresponse relationship with risk for psychopathology emerges in children as in adults. For indirect exposure, the impact may be weaker overall. However, for both types of exposure, outcomes are likely to be heterogeneous, with relatively few children facing high risk for adverse outcomes.

\section{TERRORISM RISK AND INTERVENTIONS: A DEVELOPMENTAL RESILIENCE FRAMEWORK}

Preparing to minimize the immediate and long-term consequences of terror for children and adolescents requires a developmental perspective on risk, vulnerability, and resilience. Though the literature specifically addressing protective factors and recovery of children in relation to terrorism is limited, there is a more extensive literature on other adversities that provides surprisingly consistent conclusions for conceptualizing potential preventive interventions (Garmezy and Masten, 1994; Luthar and Cicchetti, 2000; Masten, 2001; Norris et al, 2002a, b, Parts 1 and 2; Rutter, 1990, 2000; Weissberg and Kumpfer, 2003). Lessons learned to date suggest some fundamental principles for understanding, researching, and intervening to protect children in the face of terrorism.

\section{Principle 1: The Nature of the Threat must be Considered}

As noted above, children, like adults, show a dose gradient in response to direct threat. More severe reactions occur in response to events that threaten basic security (eg, a parent is killed, injured, or terrified), body and self-integrity (eg, 
the child is tortured, raped, or injured, or threatened with such), and to threats perpetrated by human design rather than natural disaster (for children old enough to understand). Secondary exposure via media and rumors is an increasing concern for children because of the degree of exposure to media among children in modern societies and the intensity of the live coverage that is now commonplace. Perceived exposure is important; studies find high symptom levels in children and adolescents who believed they had been exposed to a toxin but had not.

There is concern at all ages for the potential exacerbation of psychological reactions through media coverage, but children present a special case because of their immature cognitive abilities. Media is a powerful 'vector' by which terror spreads, using the model of infectious disease epidemiology (Butler et al, 2003). Recent survey data indicate that $36 \%$ of American children under the age of 6 have their own television in their bedroom (Rideout et al, 2003). After Oklahoma City and 9/11, television exposure in children was associated with more post-traumatic stress symptoms, at least in the short term (Pfefferbaum et al, 2001; NYC Board of Education, 2002). Some teachers in Oklahoma City chose to forego class activities in favor of watching live reports on television in the classroom. In summary, it is clear that the degree of exposure matters and that prepared adults could influence the degree of secondary exposure. While American society values not concealing things from children, and providing opportunities for them to express their fears and anxieties, there is strong evidence that younger children, at least, do better if provided with some protection from the full intensity and repeated coverage by media of trauma and disaster.

\section{Principle 2: Developmental Timing of the Terrorism will Influence Child and Family Reactions, Protections, and Developmental Sequelae}

Normative vulnerabilities, capabilities, and protective factors for processing stress shift during development (Luthar, 2003; Masten et al, 1990; Masten and Coatsworth, 1998). Infants, for example, are protected from full psychological 'exposure' to terrorism by their cognitive immaturity; most adolescents, on the other hand, are capable of apprehending the full horror of such events. Yet, infants will be highly vulnerable to degradation or destruction of caregiver function as they are totally dependent on adult care. Adolescents not only are more capable of helping themselves, having more developed human capital; they also have more extensive resources outside the family in the form of friends, teachers, and other people to go to for help, representing greater social capital.

After children form attachments to caregivers, they are highly sensitive to separation and loss, particularly if frightened (Carlson and Sroufe, 1995). Children gauge threats based on caregiver responses, a propensity termed 'social referencing.' Since terrified parents are terrifying to children, parents can moderate or mediate the propagation of terror as a vector for the spread of fear to children. Calm and functional parents, teachers, and other adults, on the other hand, can be reassuring to children.

Perceived danger and fear stimulate efforts to increase proximity to caretakers (Bowlby, 1973); people of all ages will seek contact with attachment figures, but this response will be intense in young children. It is also reciprocal, so that parents will seek physical contact with young children under conditions of extreme threat. Older children may be reassured by cell phone contact, but young children will need physical contact. Separation can be more stressful to children than the traumatic event itself (Masten et al, 1990). Though less emphasized in the literature, it is important to consider the impact of threats to children on the level of stress experienced by parents. The impact of such stress may explain particularly the strong effects of major disasters on mothers of young children (Bromet et al, 2000; Laor et al, 2001). Efforts to prepare the general population for dealing with terrorism must consider the developmental range of responses, the possible differential sensitivity of mothers to dangers and threats to their children, and the salience of attachment figures for the psychological protection of children.

Principle 3: The Experiences and Consequences for the Children in the Context of Terrorism will be Mediated and Moderated by Family, Peer, and School Systems, and Particularly by the Quality of Relationships in these Systems

Given that many effects of terrorism on children can be indirect, interventions that improve parental functioning may reduce the transmission of effects to children (eg, Dybdahl, 2001; Forgatch and DeGarmo, 1999; Wolchik et al, 2002). It is widely assumed that similar effects can be achieved through interventions with teachers. Generally, in the event of a terrorist attack, it may be more effective to target parents, teachers, and other adults close to children than children themselves, particularly in the case of younger children. Adults can act to buffer children, avoid worse situations, and ameliorate suffering. In studies of naturally occurring resilience, it is clear that effective adults function as highly adaptable protective systems for children in their care (Masten, 2001); it is not well-established whether such general competence can be taught or improved through intervention, though it is likely that specific strategies for specific threats can be learned.

\section{Principle 4: Individual Differences in Vulnerabilities and Capabilities will Influence Child Responses and Recovery Patterns}

As noted earlier, children's pre-event competence and symptoms influence how they respond to trauma (Masten et al, 1990; Norris et al, 2002a, b; Pine and Cohen, 2002). Children with mental health problems may be particularly vulnerable in part because of associated inadequacies in their external protective systems (eg, their parents may be less capable and protective) and in part due to endogenous factors. Individual risk factors also can be viewed from the perspective of protective factors; that is, children who do not have the risk factor fare better through the traumatic experience. Norris et al (Part 1) delineate such risk/ protective factors among all ages, including children. Generally, the predictors of good outcomes among children following trauma bear a striking resemblance to the 'short list' of strong protective factors in the resilience literature as 
a whole (Masten, 2001, 2004). Children functioning well prior to the experience and who have more resources available during the experience manage well under extenuating circumstances, reflecting fundamental human adaptive systems. Children lacking such protections may face the highest need for intervention.

\section{Principle 5: Interventions can be Directed at Different Phases of Terrorism, Different Processes, and Different Kinds of Children, in Different Situations}

Interventions can focus on different systems of the child's ecology or the child him/herself. The most severely threatening situations for children may involve complex processes, unfolding over time with cumulative impact. Given this possibility, a comprehensive, 'cumulative protection' model (Yates and Masten, in press; Wyman et al, 2000) may provide the most effective intervention across the widest group of children (Masten and Powell, 2003; Yoshikawa, 1994). Virtually no research examines the effectiveness of any intervention for large-scale disaster or terrorism. Clearly, this is a high priority for the nation and world community.

Preparation-phase (pre-event) strategies widely implemented in the United States for possible traumatic events include emergency plans in families, schools, and other community agencies. Schools are a particular focus of concern because of the proportion of time children spend in school and the relatively low adult-to-child ratio in schools.

Though research is of necessity constrained in disasters and emergent situations, available research on violent incidents (eg, school shootings, Oklahoma City bombing, $9 / 11$, etc) generates recommendations for intervention. These include the need for: (1) emergency plans for schools, communities, families, etc, that attend to child/family issues; (2) training of 'first responders' concerning child and family issues; (3) advising the public about developmentally appropriate media exposure; (4) effective risk communication and management or containment of fear/ symptom contagion effects. Nevertheless, more research is needed on the effectiveness of each of these and on the utility of assessment tools for triage and evaluation.

\section{Principle 6: Frontline Responders need to Know Differences between Normal and Pathological Responses to Traumatic Events as well as Strategies for Prevention}

Frontline responders include police, firefighters, medical personnel, emergency service providers, teachers, and daycare providers. These individuals need to recognize who is at greatest risk and how to differentiate typical from atypical reactions in children and parents (Pynoos et al, 1999). Sensitivity to separation stress is important, as is preparing the first responder for dealing with their reactions to child victims. The most important general observation about long-term recovery recognizes the resilience exhibited by most children. Children typically exhibit good recovery unless major protective systems for human development are damaged or destroyed (Masten, 2001). On the other hand, there is considerable evidence that traumatic experiences and disasters can have profound and lasting effects on some children.

While these general principles can inform initial efforts to minimize the effects of terrorism, clinicians and scientists both remain concerned that available research does not accurately capture the key aspects of children's responses to threats in the form of terrorism or other traumas. In particular, current research generates incomplete conclusions concerning factors that predict particularly good or dysfunctional outcomes. Moreover, limitations exist on knowledge of the mechanisms behind the effects of widely recognized risk or protective factors. Similarly, there are concerns about the possibility of slow-evolving, deleterious effects of gradual, but accumulating, impact on brain development. In each of these areas, recent advances in neurobiology generate hope that future studies will provide insights. Therefore, in the final section of this summary, data are reviewed on the relevance of basic science research on threat responses.

\section{Developmental Psychobiology}

Clinical research considering the potential impact of traumatic exposure on children's emotional well-being generates interest in the potential effects of stress on human brain development. As of this writing, virtually no research examines directly the impact of war or terrorism on human brain development. However, insights on the potential impact may emerge from the extensive basic science research on the developmental psychobiology of stress. Accordingly, the current section reviews research on developmental aspects of the stress response, with the goal of informing future studies examining psychobiological aspects of exposure to war or terrorism.

Research in the basic sciences has raised essential questions concerning developmental psychobiology and traumatic exposure. One key question concerns the role of specific brain systems in mediating a child's successful or unsuccessful adaptation to trauma. Another key question concerns the nature of any potential impact of traumatic events on the developing brain. While more data address the second question than the first, both questions arise in the wake of considerable basic science research documenting plasticity in brain systems engaged when mature organisms process threats.

Studies over the past 20 years precisely delineate the neural circuitry engaged in a range of mature mammalian species during the processing of a threatening stimulus or situation (LeDoux 1998, 2000; Davis and Whalen, 2001). While much of the initial work in this area focused on fear conditioning and learned fears (LeDoux, 2000), recent studies also examine stimuli and situations that produce fear in the absence of prior experiences with the stimulus (Davis, 1998; Blanchard et al, 2001). For most threatening situations, physiologic, cognitive, and behavioral responses in mature mammals are known to be regulated by a neural circuit encompassing the amygdala and prefrontal cortex (PFC), particularly ventral and medial aspects of the PFC (LeDoux, 1998; Rolls, 1999). For some specific types of threat, other structures also are involved, such as the bed nucleus of the stria terminalis and the hippocampus (Davis, 1998). 
Relatively few studies compare the degree to which the same or different neural structures mediate responses to threats at distinct stages of development. Synaptic connectivity within the primate amygdala reaches maturity earlier than afferent connections from the PFC or temporal cortex (Pine, 2003). As a result, potential developmental differences in the neural responses to threat have been presumed to reflect changes in major input pathways to the amygdala or interconnections among a circuit encompassing the amgydala, PFC, and other neocortical regions, as opposed to changes within intrinsic amgydala nucleii. However, lesion studies in non-human primates suggest that the developmental stage during which intrinsic amygdala dysfunction occurs strongly effects the degree to which fear behaviors are altered (Bachevalier et al, 2001; Prather et al, 2001; Amaral, 2002). As a result, developmental differences in the threat response may reflect both intrinsic immaturity within specific neural structures, as well as immaturity in the connections among these structures. Regardless, the few available studies document meaningful differences across development in the role of specific neural structures in modulating responses to threats. For example, in studies of rodents, adolescent animals exhibit a higher threshold for stress-related activation of amygdala circuitry (Kellogg et al, 1998), whereas in non-human primates, amygdala lesions have been shown to produce divergent effects on threat responses among immature as opposed to mature organisms (Amaral, 2002).

In contrast to the limited psychobiological data examining fear responses in juvenile mammals, a wealth of research examines the long-term effects of environmental factors operating early in development on threat response patterns exhibited by mature organisms (Pine, 2003). For example, rearing manipulations in rodents during the first two weeks of life have been shown to produce long-term alteration in physiology, cognition, and avoidant behavior that are readily observable in mature rodents (Liu et al, 2000; Meaney, 2001a,b). These associations are very robust, as they emerge across a range of rearing paradigms, from many laboratories, using many outcome measures. Moreover, at least for measures of behavior and physiology, other studies document parallel effects in non-human primates (Kaufman et al, 2000; Coplan et al, 2001). Finally, more recent studies in rodents document neural mediators of these developmental effects. Specifically, rearing manipulations produce long-term alterations in physiology, cognition, and behavior through effects on a neural circuit encompassing the amygdala, PFC, and hippocampus (Meaney, 2001a,b). Neuroscientists have only begun to consider the relevance of these findings for human behavior, due to noted cross-species differences in neurophysiology (Rolls, 1999). Nevertheless, knowledge concerning plasticity in brain systems engaged by threats has heightened concerns regarding the potential long-term deleterious effects of trauma or other stressful experiences in children.

A few recent basic science findings generate specific questions about children. First, cross-fostering studies in rodents suggest that experiential effects on developmental aspects of the stress response are mediated through effects on gene regulation (Francis et al, 1999, 2002; Liu et al, 2000;
Champagne and Meaney, 2001). These findings have generated particular interest on understanding interactions between the genetic and environmental factors in humans. Initial efforts to translate these insights to humans have heightened this interest. Two recent studies suggested that polymorphisms in genes that regulate serotonin and catecholamine function moderate the strength of the association between environmental stressors and risk for either major depression or behavior problems, respectively (Caspi et al, 2002, 2003). Second, gene-knockout studies suggest that genetic factors may exert different effects on stress reactivity in immature and mature organisms. For example, inactivation of the 5-HT1a receptor in a juvenile mouse produces permanent increases in stress reactivity that are not reversed by re-activation of the receptor during adulthood; conversely, inactivation of the $5 \mathrm{HT} 1 \mathrm{a}$ receptor only after a mouse has reached maturity produces no change in stress reactivity (Gross et al, 2002).

As with studies of amygdala lesions in primates, findings in rodents provide evidence of developmental variation in the relationship between brain function and stress reactivity. This has raised questions on the degree to which humans exhibit developmental variation in the relationship between neural or genetic factors and stress reactivity. Behavioral genetic studies in humans note some parallels with research in developmental neurobiology. For example, genetic factors associated with anxiety or depression in adolescents or adults exhibit weaker associations with anxiety or depression in children. Finally, much of the available research in rodents examines rearing manipulation's effects on indices of hypothalamic-pituitary-adrenal (HPA) axis function and cognitive abilities instantiated in the hippocampus. While these indices provide relatively indirect measures of neural function, noninvasive measures of these indices can be acquired in humans. Thus far, data in human children document some parallels with data in rodents, non-human primates, or adult humans (Bremner, 2001, 2002; Essex et al, 2002; Pine, 2003). However, the inconsistencies across studies of developing humans, contrasted with non-human primates and rodents, are more marked than the consistencies (Pine and Charney, 2002). This has generated considerable interest in expanding the area of inquiry in psychobiological studies among clinical samples. More direct measures of brain function in humans may facilitate efforts to extrapolate between data in humans and rodents or non-human primates.

Recent technological advances raise hopes that it will be possible to directly measure neurophysiology in children in ways that facilitate translational approaches. In particular, through advances in cognitive neuroscience, experimental paradigms have been developed that differentiate, at a behavioral or physiologic level, adult patients with PTSD from various control groups, including healthy subjects or subjects exposed to trauma who are free of PTSD symptoms (Williams et al, 1996; Grillon and Morgan, 1999; Grillon, 2002; Dalgleish et al, 2001). Through advances in fMRI, similar paradigms have been used to engage specific brain regions, such as components of the medial PFC, that are involved in stress regulation among rodents and nonhuman primates (Pine, 2003). In neuroimaging studies, some of the most successful paradigms have used photo- 
graphs of standard facial emotional expressions. For example, the viewing of faces expressing the emotion of fear consistently engages the amygdala in healthy adults, whereas the viewing of angry faces engages the ventral PFC (Haxby et al, 2002). Moreover, differences between adults with and without PTSD have been demonstrated using such paradigms (Rauch et al, 2000). Such findings generated initial interest in extending this line of inquiry to children. While only preliminary studies examine this issue, findings in children reveal some differences from findings in adults, increasing the need for basic developmental studies in children. Broadly conceptualized, these findings are consistent with data in non-human primates suggesting that specific neural structures play distinct roles in modulating fear at different stages of development. For example, in some face-viewing paradigms, children exhibit greater amygdala activation to neutral as opposed to fearful faces (Thomas et al, 2001a,b). These differences may in turn relate to developmental differences in attention during the viewing of evocative faces. In adults, attending to emotional aspects of a face has been shown to facilitate amygdala and ventral or medial PFC engagement when fear-faces are viewed (Pessoa et al, 2002). Preliminary evidence from fMRI studies suggests that this ability to modulate amygdala and PFC activity matures relatively late (Monk et al, 2003). Specifically, adults, relative to adolescents, show an enhanced capacity to regulate PFC and amygdala in concert with attention demands during the viewing of fear faces. Conversely, adolescents, relative to adults, show enhanced amygdala and PFC activation to emotionally evocative facial displays under conditions when attention is not constrained. As such, these findings suggest that the circumstances for engaging relevant neural pathways differs in meaningful ways across development.

\section{Conclusions}

More than 50 years of research from around the world can help the United States to evaluate and prepare for the possible effects of terrorism on children. Some (hopefully few) children will be directly exposed to terrorism, and some of them (though far from all) will experience symptoms of PTSD as a consequence; most will have recovered within a year provided their environment is safe. Effects of direct exposure are likely to affect a relatively limited number of children. A much larger proportion of the child population will be indirectly exposed to terrorism, through the media and other people. Here, too, a doseresponse effect is expected, which argues for adult control of the amount and content of children's exposure to the media (as well as exposure to terrified adults). Some symptoms, such as bad dreams and clinging, may occur, particularly among younger children, but these effects are unlikely to last long. A key, and potentially modifiable, predictor of children's outcomes appears to be how adults behave; parental anxieties have been found to mediate the effects of distant trauma on children's fears.

Finally, the most dangerous environments for children are those where long exposure to war and terrorism has undermined civil society, as happened in Belfast, Mozambique, and many refugee camps in the late 20th century. As in massive trauma, when all aspects of a child's ecology may have collapsed (as seen in war and natural disasters), the lives of children may be profoundly affected indirectly by the effects of the terror on the embedded systems in which they live (Wright et al, 1997). There is a real danger when order has disintegrated that frightened children will act to protect themselves by affiliating with terrorists, forming delinquent gangs, or emulating the violent behavior of adults. The undermining of civil society may be more of a threat to children's mental health in the long term than the 'distant trauma' itself.

\section{REFERENCES}

Allwood M, Bell-Dolan D, Husain S (2002). Children's trauma and adjustment reactions to violent and nonviolent war experiences. J Am Acad Child Adolesc Psychiatry 41: 450-457.

Amaral DG (2002). The primate amygdala and the neurobiology of social behavior: implications for understanding social anxiety. Biol Psychiatry 51: 11-17.

Asarnow J, Glynn S, Pynoos R, Nahum J, Guthrie D, Cantwell DP et al (1999). When the earth stops shaking: Earthquake sequelae among children diagnosed for pre-earthquake psychopathology. J Am Acad Child Adolesc Psychiatry 38: 1016-1023.

Bachevalier J, Malkova L, Mishkin M (2001). Effects of selective neonatal temporal lobe lesions on socioemotional behavior in infant rhesus monkeys (Macaca mulatta). Behav Neurosci 115: 545-559.

Blanchard CD, Hynd AL, Minke KA, Minemoto T, Blanchard RJ (2001). Human defensive behaviors to threat scenarios show parallels to fear- and anxiety-related defense patterns of nonhuman mammals. Neurosci Biobehav Rev 25: 761-770.

Bowlby J (1973). Attachment and Loss: Vol. 2. Separation. Basic Books: New York.

Bremner JD (2002). Neuroimaging of childhood trauma. Semin Clin Neuropsychiatry 7: 104-112.

Bremner JD. (2001). Hypotheses and controversies related to effects of stress on the hippocampus: an argument for stressinduced damage to the hippocampus in patients with posttraumatic stress disorder. Hippocampus 11: 75-81 discussion 82-84.

Brener N, Simon T, Anderson M, Barrios L, Small M (2002). Effect of the incident at Columbine on student's violence- and suiciderelated behaviors. Am J Prev Med 22: 146-150.

Breslau N (2002). Psychiatric morbidity in adult survivors of childhood trauma. Sem Clin Neuropsychiatry 7: 80-88.

Bromet E, Goldgaber D, Carlson G, Panina N, Golovakha E, Gluzman S et al (2000). Children's well-being 11 years after the Chernobyl catastrophe. Arch Gen Psychiatry 57: 563-571.

Butler AS, Panzer AM, Goldfrank LR (2003). Preparing for the Psychological Consequences of Terrorism: A Public Health Strategy. Institute of Medicine of the National Academies, National Academies Press: Washington, DC (www.nap.edu).

Carlson EA, Sroufe LA (1995). The contribution of attachment theory to developmental psychopathology. In: D Cohen (ed). Developmental Processes and Psychopathology: Vol. 1. Theoretical Perspectives and Methodological Approaches. Cambridge University Press: New York. pp 581-617.

Caspi A, McClay J, Moffitt TE, Mill J, Martin J, Craig IW et al (2002). Role of genotype in the cycle of violence in maltreated children. Science 297: 851-854.

Caspi A, Sugden K, Moffitt TE, Taylor A, Craig IW, Harrington H et al (2003). Influence of life stress on depression: moderation by a polymorphism in the 5-HTT gene. Science 301: 386-389.

Champagne F, Meaney MJ (2001). Like mother, like daughter: evidence for non-genomic transmission of parental behavior and stress responsivity. Prog Brain Res 133: 287-302. 
Champion LA, Goodall G, Rutter M (1995). Behavior problems in childhood and stressors in early adult life. I. A 20 year follow-up of London school children. Psychol Med 25: 231-246.

Chase R, Doney A, Sivayogan S, Ariyaratne V, Satkunanayagam P, Swaminathan A (1999). Mental health initiatives as peace initiatives in Sri Lankan schoolchildren affected by armed conflict. Med Confl Surviv 15: 379-390.

Coplan JD, Smith EL, Altemus M, Scharf BA, Owens MJ, Nemeroff $\mathrm{CB}$ et al (2001). Variable foraging demand rearing: sustained elevations in cisternal cerebrospinal fluid corticotropin-releasing factor concentrations in adult primates. Biol Psychiatry 50: 200-204.

Cornely P, Bromet E (1986). Prevalence of behavior problems in three-year-old children living near Three Mile Isalnd: A comparitive analysis. J Am Acad Child Adolesc Psychiatry 27: 489-498.

Costello EJ, Erkanli A, Fairbank JA, Angold A (2002). The prevalence of potentially traumatic events in childhood and adolescence. J Trauma Stress 15: 99-112.

Dalgleish T, Moradi AR, Taghavi MR, Neshat-Doost HT, Yule W (2001). An experimental investigation of hypervigilance for threat in children and adolescents with post-traumatic stress disorder. Psychol Med 31: 541-547.

Davis M (1998). Are different parts of the extended amygdala involved in fear versus anxiety? Biol Psychiatry 44: 1239-1247.

Davis M, Whalen PJ (2001). The amygdala: vigilance and emotion. Mol Psychiatry 6: 13-34.

Dybdahl R (2001). Children and mothers in war: an outcome study of a pscyhosocial intervention program. Child Dev 72: 1214-1230.

Dyregrov A, Gupta L, Gjestad R, Mukanoheli E (2000). Trauma exposure and psychological reactions to genocide among Rwandan children. J Trauma Stress 13: 3-21.

Eley TC, Bolton D, O'Connor TG, Perrin S, Smith P, Plomin R (2003). A twin study of anxiety-related behaviors in pre-school children. Child Psychol Psychiatry 44: 945-960.

Eley TC, Stevenson J (2000). Specific life events and chronic experiences differentially associated with depression and anxiety in young twins. J Abnorm Child Psychol 28: 383-394.

Essex MJ, Klein MH, Cho E, Kalin NH (2002). Maternal stress beginning in infancy may sensitize children to later stress exposure: effects on cortisol and behavior. Biol Psychiatry 52: 776-784.

Forgatch MS, DeGarmo DS (1999). Parenting through change: an effective prevention program for single mothers. J Consult Clin Psychol 67: 711-724.

Francis D, Diorio J, Liu D, Meaney MJ (1999). Nongenomic transmission across generations of maternal behavior and stress responses in the rat. Science 286: 1155-1158.

Francis DD, Diorio J, Plotsky PM, Meaney MJ (2002). Environmental enrichment reverses the effects of maternal separation on stress reactivity. J Neurosci 22: 7840-7843.

Garmezy N, Masten AS. (1994) Chronic adversities. In: Rutter M, Herzov L, Taylor E (eds). Child and Adolescent Psychiatry. Blackwell Scientific Publications: Oxford. pp 191-208.

Gorman-Smith D, Tolan P (1998). The role of exposure to community violence and developmental problems among inner-city youth. Dev Psychopathol 10: 101-116.

Grillon C (2002). Startle reactivity and anxiety disorders: aversive conditioning, context, and neurobiology. Biol Psychiatry 15: 958-975.

Grillon C, Morgan CA (1999). Abnormal mismatch negativity in women with sexual assault-related posttraumatic stress disorder. Biol Psychiatry 45: 827-832.

Gross C, Zhuang X, Stark K, Ramboz S, Oosting R, Kirby L et al (2002). Serotonin1A receptor acts during development to establish normal anxiety-like behaviour in the adult. Nature 416: 396-400.
Hadi F, Llabre M (1998). The Gulf crisis experience of Kuwaiti children: psychological and cognitive factors. J Trauma Stress 11: 45-56.

Haxby JV, Hoffman EA, Gobbini MI (2002). Human neural systems for face recognition and social communication. Biol Psychiatry 51: 59-67.

Hetherington EM (ed). (1999). Coping with Divorce, Single Parenting and Remarriage: A Risk and Resiliency Perspective. Erlbaum: Mahwah, NJ.

Hoven C, Duarte C, Mandell D (2003). Children's mental health after disasters: the impact of the World Trade Center attack. Curr Psychiatry Rep 5: 101-107.

Hubbard J, Realmuto GM, Northwood AK, Masten AS (1995). Comorbidity of psychiatric diagnoses with post-traumatic stress disorder in survivors of childhood trauma. J Am Acad Child Adolesc Psychiatry 34: 1167-1173.

Kaufman J, Plotsky PM, Nemeroff CB, Charney DS (2000). Effects of early adverse experiences on brain structure and function: clinical implications. Biol Psychiatry 48: 778-790.

Kellogg CK, Awatramani GB, Piekut DT (1998). Adolescent development alters stressor-induced Fos immunoreactivity in rat brain. Neuroscience 83: 681-689.

Kendler KS, Hettema JM, Butera F, Gardner CO, Prescott CA (2003). Life event dimensions of loss, humiliation, entrapment, and danger in the prediction of onsets of major depression and generalized anxiety. Arch Gen Psychiatry 60: 789-796.

Kitzmann KM, Gaylord NK, Holt AR, Kenny ED (2003). Child witnesses to domestic violence: a meta-analytic review. J Consult Clin Psychol 71: 339-352.

Kostinsky S, Bixler E, Kettl P (2001). Threats of school violence in Pennsylvania after media coverage of the Columbine high school massacre: examining the role of imitation. Arch Pediatr Adolesc Med 155: 994-1001.

Laor N, Wolmer L, Cohen DJ (2001). Mothers' function and children's symptoms 5 years after a SCUD missile attack. Am J Psychiatry 158: 1020-1026.

LeDoux J (1998). Fear and the brain: where have we been, and where are we going? Biol Psychiatry 44: 1229-1238.

LeDoux JE (2000). Emotion circuits in the brain. Annu Rev Neurosci 23: 155-184.

Liu D, Diorio J, Day JC, Francis DD, Meaney MJ (2000). Maternal care, hippocampal synaptogenesis and cognitive development in rats. Nat Neurosci 3: 799-806.

Llabre M, Hadi F (1997). Social support and psychological distress in Kuwaiti boys and girls exposed to the Gulf crisis. J Clin Child Psychol 26: 247-255.

Luthar SS (ed) (2003). Resilience and Vulnerability: Adaptation in the Context of Childhood Adversities. Cambridge University Press: New York.

Luthar SS, Cicchetti D (2000). The construct of resilience: Implications for interventions and social policies. Dev Psychopathol 12: 857-885.

Lyons H (1979). Civil violence-the psychological aspects. J Psychosom Res 23: 373-393.

Masten AS (2004). Regulatory processes, risk, and resilience in adolescent development. Ann NY Acad Sci 1021: 310-319.

Masten AS, Best KM, Garmezy N (1990). Resilience and development: Contributions from the study of children who overcome adversity. Dev Psychopathol 2: 425-444.

Masten AS, Coatsworth JD (1998). The development of competence in favorable and unfavorable environments: Lessons from successful children. Am Psychol 53: 205-220.

Masten AS, Powell JL (2003). A resilience framework for research, policy, and practice. In: Luthar SS (ed). Resilience and Vulnerability: Adaptation in the Context of Childhood Adversities. Cambridge University Press: New York. pp 1-25.

Masten AS, Wright MO (1998). Cumulative risk and protection models of child maltreatment. J Aggression Maltreatment Trauma 2: 7-30. 
Meaney MJ (2001a). Nature, nurture, and the disunity of knowledge. Ann NY Acad Sci 935: 50-61.

Meaney MJ (2001b). Maternal care, gene expression, and the transmission of individual differences in stress reactivity across generations. Annu Rev Neurosci 24: 1161-1192.

Merikangas KR, Avenevoli S, Dierker L, Grillon C (1999). Vulnerability factors among children at risk for anxiety disorders. Biol Psychiatry 46: 1523-1535.

Mollica R, Poole C, Son L, Murray C, Tor S (1997). Effects of war trauma on Cambodian refugee adolescents' functional health and mental health status. J Am Acad Child Adolesc Psychiatry 36: 1098-1106.

Monk C, McClure EB, Nelson EB, Zarahn E, Bilder RM, Leibenluft $\mathrm{E}$ et al (2003). Adolescent immaturity in attention-related brain engagement to emotional facial expressions. NeuroImage 20: 420-428.

Moore MH, Petrie CV, Braga AA, McLaughlin BL (2002). Deadly Lessons: Understanding Lethal School Violence. National Research Council: Washington, DC.

New York City Board of Education (2002). Effects on the World Trade Center Attack on NYC School Students. Applied Research and Consulting, LLC, Columbia University Mailman School of Public Health, and New York Sate Psychiatric Institute: New York, NY, May 6, 2002.

Norris FH, Friedman MJ, Watson P (2002a). 60,000 disaster victims speak: Part II. Summary and implications of the disaster mental health research. Psychiatry 65: 240-260.

Norris FH, Friedman MJ, Watson PJ, Byrne CM, Diaz E, Kaniasty K (2002b). 60,000 Disaster victims speak: Part I. An empirical review of the empirical literature, 1981-2001. Psychiatry 65: 207-239.

Papageorgiou V, Frangou-Garunovic A, Iordanidou R, Yule W, Smith PD, Vostanis P (2000). War trauama and psychopathology in Bosnian refugee children. Eur Child Adolesc Psychiatry 9: 84-90.

Pessoa, L, McKenna M, Gutierrez E, Ungerleider LG (2002). Neural processing of emotional faces requires attention. Proc Natl Acad Sci USA. 99: 11458-11463.

Pfefferbaum B, Doughty D, Gurwitch R, North C, Fullerton C, Kyula J (2003a). Posttraumatic stress and functional impairment in Kenyan children following the 1998 American Embassy bombing. Am J Orthopsychiatry 73: 133-140.

Pfefferbaum B, Nixon SJ, Tivis RD, Doughty DE, Pynoos RS, Gurwitch RH et al (2001). Television exposure in children after a terrorist incident. Psychiatry 64: 202-211.

Pfefferbaum B, Pfefferbaum R, Gurwitch R, Nagumalli S, Brandt E, Robertson M et al (2003b). Children's response to terrorism: a critical review of the literature. Curr Psychiatry Rep 5: 95-100.

Pine D, Charney D (2002). Children, stress, and sensitization: an integration of basic and clinical research on emotion? Biol Psychiatry 52: 773.

Pine DS (2003). Developmental psychobiology and response to threats: relevance to trauma in children and adolescents. Biol Psychiatry 53: 796-808.

Pine DS, Cohen JA (2002). Trauma in children and adolescents: risk and treatment of psychiatric sequelae. Biol Psychiatry 51: 519-531.

Pine DS, Cohen P, Johnson JG, Brook JS (2002). Adolescent life events as predictors of adult depression. I Affect Disord 68: 49-57.

Prather MD, Lavenex P, Mauldin-Jourdain ML, Mason WA, Capitanio JP, Mendoza SP et al (2001). Increased social fear and decreased fear of objects in monkeys with neonatal amygdala lesions. Neuroscience 106: 653-658.

Pynoos RS, Steinberg AM, Piacentini JC (1999). A developmental psychopathology model of childhood traumatic stress and intersection with anxiety disorders. Biol Psychiatry 46: $1542-1554$.
Rauch SL, Whalen PJ, Shin LM, McInerney SC, Macklin ML, Lasko $\mathrm{NB}$ et al (2000). Exaggerated amygdala response to masked facial stimuli in posttraumatic stress disorder: a functional MRI study. Biol Psychiatry. 47: 769-776.

Rideout VJ, Vandewater EA, Wartella EA (2003). Zero to six: electronic media in the lives of infants, toddlers, and preschoolers. A Kaiser Family Foundation Report.

Rolls E (1999). The Brain and Emotion. Oxford University Press: Oxford, England.

Rutter M. (1990). Psychosocial resilience and protective mechanisms. In: Rolf J, Masten AS, Cicchetti D, Nuechterlein $\mathrm{KH}$, Weintraub S (eds). Risk and Protective Factors in the Development of Psychopathology. Cambridge University Press: New York. pp 181-214.

Rutter M (2000). Resilience reconsidered: Conceptual considerations, empirical findings, and policy implications. In: Shonkoff JP, Meisels SJ (eds). Handbook of Early Intervention, 2nd edn. Cambridge University Press: New York. pp 651-681.

Sack W, Him C, Dickason D (1999). Twelve-year follow-up study of Khmer youths who suffered massive war trauma as children. J Am Acad Child Adolesc Psychiatry 38: 1173-1179.

Sagi-Schwartz A, van Ijzendoorn M, Grossmann K, Joels T, Grossmann K, Scharf M et al (2003). Attachment and traumatic stress in female Holocaust child survivors and their daughters. Am J Psych 160: 1082-1086.

Schwarzwald J, Weisenberg M, Waysman M, Solomon Z, Klingman A (1993). Stress reaction of school-age children to the bombardment by SCUD missles. J Abnorm Psychol 102: 404-410.

Shaw JA, Applegate B, Tanner S, Perez D, Rothe E, Campo-Bowen AE et al (1995). Psychological effects of Hurricane Andrew on an elementary school population. J Am Acad Child Adolesc Psychiatry 34: 1185-1192.

Stein B, Comer D, Gardner W, Kelleher K (1999). Prospective study of displaced children's symptoms in wartime Bosnia. Soc Psychiatry Pscyhiatr Epidemiol 34: 464-469.

Steinberg L, Avenevoli S (2000). The role of context in the development of psychopathology: a conceptual framework and some speculative propositions. Child Dev 71: 66-74.

Terr L, Bloch D, Michel B, Shi H, Reinhardt J, Metayer S (1999). Children's symptoms in the wake of Challenger: a field study of distant-traumatic effects and an outline of related conditions. Am J Psychiatry 156: 1536-1544.

Thabet A, Vostanis P (1999). Post-traumatic stress reaction in children of war. J Child Psychol Psychiatry 40: 385-391.

Thabet A, Vostanis P (2000). Post traumatic stress disorder reactions in children of war: a longitudinal study. Child Abuse Neglect 24: 291-298.

Thabet AAM, Abed Y, Vostanis P (2004). Comorbidity of PTSD and depression among refugee children during war conflict. J Child Psychol Psychiatry 45: 533-542.

Thomas KM, Drevets WC, Dahl RE, Ryan ND, Birmaher B, Eccard CH et al (2001a). Amygdala response to fearful faces in anxious and depressed children. Arch Gen Psychiatry 58: 1057-1063.

Thomas KM, Drevets WC, Whalen PJ, Eccard CH, Dahl RE, Ryan ND et al (2001b). Amygdala response to facial expressions in children and adults. Biol Psychiatry 49: 309-316.

US Committee for Refugees (2004). World Refugee Survey 2004. May 2004.

Weine S, Becker D, McGlashan T, Vojvoda D, Hartman S, Robbins J (1995). Adolescent survivors of 'Ethnic Cleansing': observations on the first year in America. J Am Acad Child Adolesc Psychiatry 34: 1153-1159.

Weissberg RP, Kumpfer KL (2003). Special issue: prevention that works for children and youth. Am Psychol 58: 425-490.

Weissman MM, Warner V, Wickramarante P, Moreau D, Olfson, M (1997). Offspring of depressed parents. 10 years later. Arch Gen Psychiatry 55: 932-940. 
Williams JM, Mathews A, MacLeod C (1996). The emotional stroop task and psychopathology. Psychol Bull 120: 3-24.

Wolchik SA, Sandler IN, Millsap RE, Plummer BA, Greene SM, Anderson ER et al (2002). Six-year follow-up of a randomized, controlled trial of preventive interventions for children of divorce. JAMA 288: 1874-1881.

Wolfe DA, Crooks C, Lee V, McIntyre-Smith A, Jaffe P (2003). The effects of children's exposure to domestic violence: a metaanalysis and critique. Clin Child Fam Psychol Rev 6: 171-187.

Wright MO, Masten AS, Northwood A, Hubbard JJ (1997). Longterm effects of massive trauma: developmental and psychobiological perspectives. In: Cicchetti D, Toth SL (eds). Rochester Symposium on Developmental Psychopathology. The Effects of Trauma on the Developmental Process, Vol 8. University of Rochester Press: Rochester. pp 181-225.
Wyman PA, Sandler I, Wolchik S, Nelson K (2000). Resilience as cumulative competence promotion and stress protection: theory and intervention. In: Cicchetti D, Rappaport J, Sandler I, Weissberg RP (eds). The Promotion of Wellness in Children and Adolescents. Child Welfare League of America Press: Washington, DC. pp 1-184.

Yates TM, Masten AS. (in press). Fostering the future: Resilience theory and the practice of positive psychology. In: Linley PA, Joseph S (eds). Positive Psychology in Practice. Wiley: Hoboken, NJ.

Yoshikawa H (1994). Prevention as cumulative protection: effects of early family support and education on chronic delinquency and its risks. Psychol Bull 115: 28-54.

Yehuda R (2002). Post-traumatic stress disorder. N Engl J Med 346: 108-114. 